Article

\title{
Enhancing Pre-Service Special Educator Preparation through Combined Use of Virtual Simulation and Instructional Coaching
}

\author{
Maria Peterson-Ahmad \\ Division of Education and Leadership, Western Oregon University, 345 Monmouth Ave. N., Monmouth, \\ OR 97361, USA; petersonahmadm@wou.edu
}

Received: 30 December 2017; Accepted: 9 January 2018; Published: 11 January 2018

\begin{abstract}
To meet the ever-increasing teaching standards, pre-service special educators need extensive and advanced opportunities for pedagogical preparation prior to entering the classroom. Providing opportunities for pre-service special educators to practice such strategies within a virtual simulation environment offers teacher preparation programs a way to individualize the teaching and practice of various pedagogical aspects needed when new educators enter their first classroom. Coupling such simulations with specific instructional coaching allows for increased and individualized remediation of the way instruction is given, classroom management practices, or getting to know your student population. This exploratory case study investigated the extent to which virtual simulations combined with instructional coaching impacted the way pre-service educators learned how to provide opportunities to respond (OTR) to the avatar students through the repeated teaching of a lesson over four sessions.
\end{abstract}

Keywords: instructional coaching; opportunities to respond; pre-service educators; virtual simulation

\section{Introduction}

Teacher preparation programs are challenged with training high-quality educators' who can work effectively with all students (with and without disabilities) and simultaneously raise student achievement [1]. Teacher preparation programs must continually examine the variety of objectives and outcome variables associated with effective teacher performance and assess pre-service teachers' knowledge and instructional experiences so that the delivery and differentiation of instruction broadens and enhances teaching skills for students with and without a disability [2-4]. Research documents a positive correlation between pre-service educators pedagogical preparation in content matter and performance in the classroom and has recognized that teachers who have had advanced preparation in teaching methodologies and strategies have a greater chance of longevity in the classroom $[5,6]$. When teachers are well prepared in content and pedagogy, it makes an enormous difference not only in their effectiveness in the classroom, but also if they are likely to stay in the teaching profession [7]. Utilizing a virtual simulation is one approach that can be applied in pre-service teacher education preparation programs.

Research supports the use of multimedia (such as a virtual simulation) that allows pre-service educators a combination of learning in content knowledge, teaching pedagogy, and problem-solving skills [8,9]. Virtual simulations provide the opportunity to supplement course content and field-based experiences by allowing practice and refinement of instructional strategies in a low risk environment, including (but not limited to): teaching of subject area content; data collection; individualizing and differentiating learning opportunities; classroom management.

This exploratory case study aimed to investigate how virtual simulations, in combination with instructional coaching from mentor teacher preparation faculty, could be used to transform early 
learning experiences with pre-service educators, specifically teaching how to effectively provide opportunities to respond so that teachers provide stimuli that warrant student responses.

\section{Virtual Simulation}

A virtual simulation can be defined as the combination of real and virtual worlds that provide users with a sense of presence. As efforts to improve teacher preparation programs continue and evidence of the benefits of experiential learning effectiveness grows, so does the need for innovative ways to incorporate such aspects into higher education courses [10]. The need for the use of such environments in teacher preparations programs is growing because of the changing demographics of both students and teachers in today's schools; therefore, virtual simulations have the opportunity to potentially change the way in which pre-service educators are trained.

This exploratory case study utilized the TeachLivE ${ }^{\mathrm{TM}}$ mixed-reality, virtual learning simulated environment. TeachLivE ${ }^{\mathrm{TM}}$ allows for the development of early teaching skills and assists in the fine-tuning of specific strategies. The TeachLivE ${ }^{\mathrm{TM}}$ simulated environment is comprised of five avatar students that provide a unique setting for pre-service educators opportunities to experience various student characteristics and learn about specific teaching approaches [3]. Each avatar student is unique in that they represent an array of demographics and personalities. This virtual simulation immerses pre-service educators into a setting that is meant to replicate a classroom and allows participants the opportunity to interact with the virtual students where they can review previous work, present new content to students, or provide scaffolding/guided practice in a variety of content areas to monitor students while they work independently [3]. Virtual simulations like TeachLivE ${ }^{\mathrm{TM}}$ allow individuals to have repeated (teaching) trials involving high stakes situations without risking the loss of valuable resources (e.g., money, time, and people) [3]. Experiences in the TeachLivE ${ }^{\mathrm{TM}}$ virtual simulation enable pre-service teachers to transfer knowledge learned from college coursework and apply it in the context of the virtual classroom, thereby solidifying and deepening understanding of skills and providing contextualized professional development. These experiences, in combination with after-action review, create opportunities to further construct beliefs and practices that are grounded in teaching experiences [11,12].

\section{Instructional Coaching}

Instructional coaching can be described as a partnership between a mentor educator and pre-service educator to gauge present levels of teaching and to set/revise goals. It allows educators the opportunity to practice and gain confidence in the use of an increasingly powerful repertoire of instruction methods. Instructional coaching also creates a rich dialogue between mentor educator and pre-service educators that can improve the quality and clarity of instruction by further developing educational experiences through the development of early dispositions for collaboration and continuous improvement, and allowing pre-service educators the opportunity to contextualize experiences, reflect on teaching, and understand why interim objectives were or were not accomplished [12,13]. Instructional coaching creates opportunities for the construction and transformation of beliefs and practices grounded in teaching experiences, in addition to solidifying and deepening understanding of skills used in the teaching profession, improving early instructional practices, observing results, and evaluating effects on student outcomes [11,14]. Exposure to early and multiple instructional coaching experiences helps to prepare pre-service educators to more thoughtfully meet the many demands in today's schools [15].

\section{Opportunities to Respond}

Opportunities to respond (OTR) are actions that occasion a response. For example, the teacher presenting a student with a request to respond (i.e., antecedent stimulus), giving the student an opportunity to respond to the antecedent stimulus, and then once a response is produced (or not produced), the teacher gives the student feedback [16]. Learning how to provide OTR in pre-service 
teacher preparation programs is vital as it has been linked as an indicator of effective instruction, improved student achievement, as well as improved student performance and behavior [17,18]. When adequate OTR are presented, it allows teachers to elicit feedback from students and to adjust instruction based on perceived student understanding. These variables coincide to maximize student achievement and establish a climate that values justification, conjecture, and the co-construction of knowledge $[19,20]$.

Numerous research studies have identified the efficacy of providing students (with and without disabilities) increased teacher-directed OTR across a variety of student behaviors (e.g., on-task, disruptive, academically engaged, and active responding behavior [21]. Research studies have determined that for students with high incidence disabilities (i.e., learning disabilities), a suggested a rate of approximately three to five teacher-directed OTR per minute are associated with positive student outcomes [22]. When teachers generated OTR, they increased the likelihood of desired responses from students, whether through incorporated strategies of presentation materials, asked questions, or corrected student answers [23].

\section{Materials and Methods}

This pilot study utilized an exploratory case-study design to determine whether or not the combined use of TeachLivE ${ }^{\mathrm{TM}}$ and instructional coaching with pre-service special educators impacted their use of providing opportunities to respond within the virtual simulated environment. This exploratory case study was guided by the following research questions:

1. How does time in the TeachLivE ${ }^{\mathrm{TM}}$ virtual learning environment impact pre-service educators frequency of providing OTR?

2. How does time in the TeachLivE ${ }^{\mathrm{TM}}$ virtual learning environment coupled with instructional coaching impact pre-service special educators' frequency of providing OTR?

3. How does time in the TeachLivE ${ }^{\mathrm{TM}}$ virtual learning environment impact teaching practices and perceptions?

Participants included $N=8$ undergraduate pre-service special education teachers enrolled in an initial certification teacher preparation program and were randomly selected from a pool based on interest in participating in the study. Each participant completed four TeachLivE ${ }^{\mathrm{TM}}$ virtual simulations over a five-week period. Half of the pre-service participants (Case Study Group 1) $(N=4)$ received instructional coaching after all TeachLivE ${ }^{\mathrm{TM}}$ simulations, while the other half (Case Study Group 2) did not receive any instructional coaching (Table 1). All aspects of this study were approved by the university Institutional Review Board (IRB) and consent for participation was received from all participants prior to any data collection.

Table 1. Participant involvement in research study.

\begin{tabular}{lll}
\hline Participants & TeachLivE $^{\mathrm{TM}}$ (Four Sessions) & Instructional Coaching \\
\hline $\begin{array}{l}\text { Case Study Group 1 } \\
N=4\end{array}$ & $\mathrm{X}$ & $\mathrm{X}$ \\
\hline $\begin{array}{l}\text { Case Study Group 2 } \\
N=4\end{array}$ & $\mathrm{X}$ & \\
\hline
\end{tabular}

During each simulated session, participants taught a lesson out of the Focusing Together: Promoting Self-Management Skills in the Classroom [24], which emphasized learning expectations to promote responsible work habits and respect. Frequency counts were tallied up for how often the pre-service special educators provided OTR during each session (see examples of frequency count categories in Table 2). Instructional coaching was provided to Case Study Group 1 following each virtual simulation that focused on how many OTR were provided and setting goals for how to modify instruction and increase delivery of OTR for future sessions. 
Table 2. Categories with examples of observed opportunities to respond (OTR).

\begin{tabular}{|c|c|c|c|c|}
\hline $\begin{array}{l}\text { Scripted (Verbatim from } \\
\text { a Lesson or Curriculum) }\end{array}$ & $\begin{array}{l}\text { Yes/No (Closed } \\
\text { Response) }\end{array}$ & $\begin{array}{l}\text { Original (Comes } \\
\text { up with on Own) }\end{array}$ & Management & Behavioral \\
\hline $\begin{array}{l}\text { "What is a learning } \\
\text { community?" }\end{array}$ & $\begin{array}{l}\text { "Do you agree } \\
\text { with my } \\
\text { answer?" }\end{array}$ & $\begin{array}{l}\text { "With a peer, } \\
\text { brainstorm an } \\
\text { example of what it } \\
\text { means to be a good } \\
\text { friend". }\end{array}$ & $\begin{array}{l}\text { "What items } \\
\text { should be on your } \\
\text { desk in order to be } \\
\text { prepared for this } \\
\text { lesson?" }\end{array}$ & $\begin{array}{l}\text { "What should } \\
\text { we remember } \\
\text { to do before } \\
\text { blurting out } \\
\text { an answer?" }\end{array}$ \\
\hline
\end{tabular}

All participants $(N=8)$ completed self-reflections following all TeachLivE ${ }^{\mathrm{TM}}$ virtual simulations and responded to the following reflection based prompts: (1) How did you feel (overall) about your simulation session? (2) What things do you feel went well?, and; (3) What areas do you feel could be improved upon for your next simulation session? These questions were also used in discussions with the Case Study Group 1 (receiving instructional coaching) to assist in the development of goals for future sessions.

\section{Results}

\subsection{OTR Frequency Data}

Across all participants $(N=8)$, four increased their overall frequency of providing teacher-directed opportunities to respond between initial and final virtual simulation sessions. Half of the participants showing such improvement were from the group that received after-action review and the other half were not (Figures 1 and 2). Two participants in Case Study Group 1 (after-action review received) who increased in providing OTR between the initial and final sessions had an increase of +15 with an average rate of $21 \mathrm{OTR} /$ per minute and an increase of +2 with an average rate of $21 \mathrm{OTR} /$ per minute. Interestingly, two participants in the control group also increased in providing OTR between the initial and final virtual simulation sessions and had an increase of +10 with an average of 19 OTR/per minute and an increase of +7 with an average rate of 25 OTR/per minute (Table 3 ).

Among both case study groups $75 \%$ of participants decreased in their overall use of scripted OTR (questions verbatim from the Focusing Together lesson plan), 50\% decreased their use of close-ended (yes/no) OTR, and 75\% increased use of management related (attention getting, supplies needed, etc.) OTR. Because behaviors exhibited by the avatars varied from session to session, data was inconclusive regarding behavioral OTR, however, $100 \%$ of participants increased their use of original type OTR between the first and final TeachLivE ${ }^{\mathrm{TM}}$ sessions.

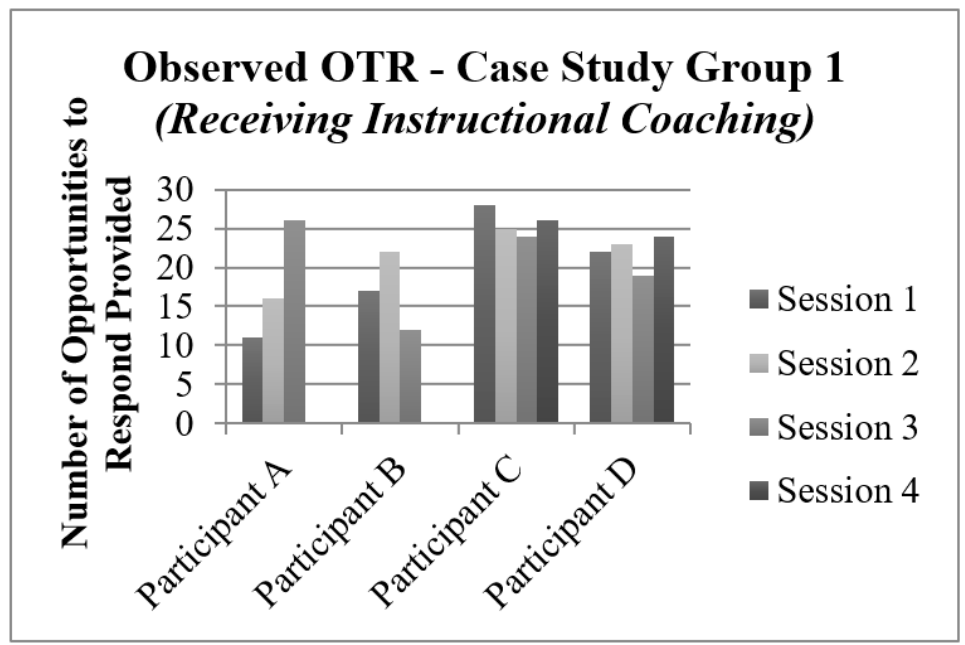

Figure 1. Observed OTR during duration of study; instructional coaching received. 


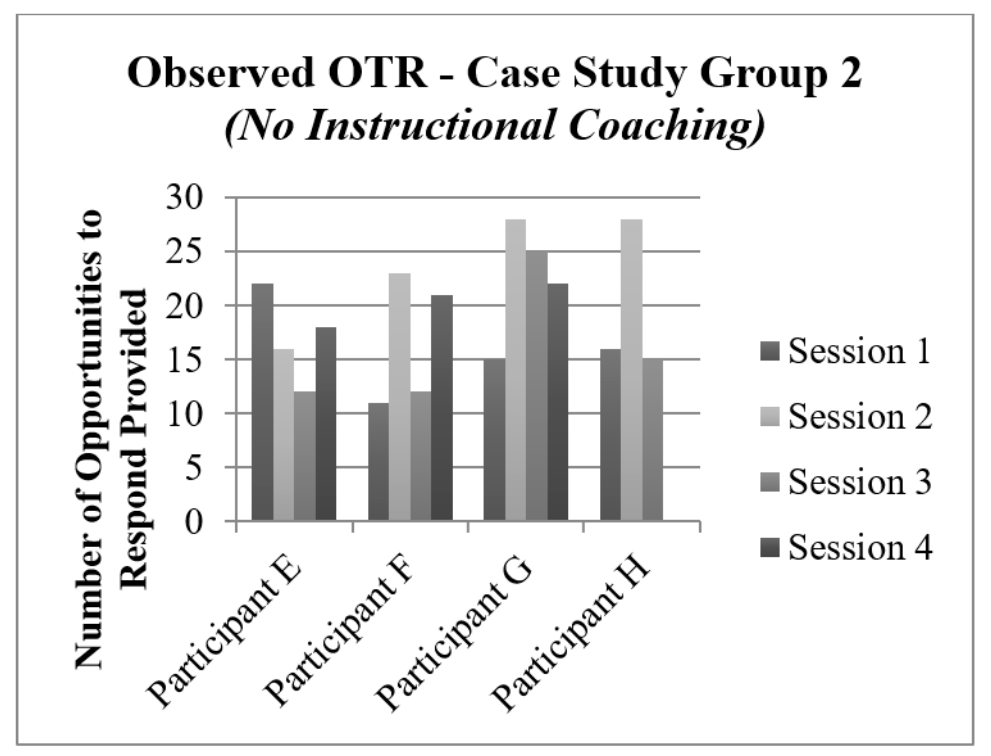

Figure 2. Observed OTR during duration of study; no instructional coaching received.

Table 3. Overall participant results of providing OTR.

\begin{tabular}{llll}
\hline Participant & $\begin{array}{l}\text { Session 1 \# OTR } \\
\text { Baseline }\end{array}$ & $\begin{array}{l}\text { Change in \# OTR Between } \\
\text { First \& Last Sessions }\end{array}$ & $\begin{array}{l}\text { Average Rate of OTR } \\
\text { Provided/Minute }\end{array}$ \\
\hline Case Study Group & 1-Instructional Coaching Received & \\
A & 11 & +15 & 21 \\
B & 17 & -5 & 17 \\
C & 28 & -2 & 25 \\
D & 22 & +2 & 21 \\
\hline Case Study Group 2-No Instructional Coaching & & \\
E & 22 & -4 & 15 \\
F & 11 & +10 & 19 \\
G & 15 & +7 & 25 \\
H & 16 & -1 & 21 \\
\hline
\end{tabular}

\subsection{Self-Reflection Data}

Participant self-reflections were analyzed and coded using NVivo. Through this process, the following common themes emerged: (1) positive comments; (2) negative comments; (3) things to change for the next session, and; (4) feelings about providing OTR. Qualitative analysis yielded that overall, participants self-reflected: $17.43 \%$ positive type statements; $3.66 \%$ negative statements; $21.81 \%$ things to change for next time statements, and; $17.74 \%$ statements regarding overall feelings about providing OTR. Specific avatar student characteristics also surfaced among participant reflections with regards to how participants wanted to better incorporate individualized student needs into their teaching. This was evident from case study group 1 which included the following specific comment regarding pedagogical disposition: "Really started to see what each student was doing while we were discussing and I noticed things that they would do when I was speaking to them specifically". Many participants indicated changes that needed to be made in the way that opportunities to respond were provided regarding increased self-reflection practices: "I felt as if I gave all students a chance to speak, however, when probing, I did not always provide room for students to make connections. I feel as if my questions were not always clear". Figure 3 represents the overall frequency of words and phrases used most frequently across all participant self-reflections; larger words represent more frequent usage. 


\section{suturantatura self-reflection StudentAttitudes ChangelnTeaching TeachlivE individualization Lessonchange}

Figure 3. Words most frequently used among participant self-reflections and anecdotal data.

After-action review anecdotal notes taken by the researcher during the virtual simulations, noted that participants observed specific student characteristics of the student avatars within the TeachLivE ${ }^{\mathrm{TM}}$ virtual learning environment and learned how to incorporate the individualized student needs into their teaching: “Try to incorporate everyone because I left one avatar completely out today; I didn't call on them once!" Many participants had a realization of changes that needed to be made in the way that OTR were provided: "I feel I could have given more wait time as they begin to talk" or, "I could have used more open-ended questions". This data may infer that instructional coaching was an effective tool that allowed for further reflection beyond participants own thinking processes and knowledge base.

When analyzing and triangulating the case study data, several themes emerged. First, participants specifically spoke about how to further engage the student avatars in the TeachLivE ${ }^{\mathrm{TM}}$ virtual learning environment in regards to lessons and on an even more individualized level. This data infers that participants started to take note of individual avatar student personalities and behaviors within the classroom and thought about how to best involve and connect with the various types of learners to minimize disruptions (blurting, interruptions, student disengagement during lessons, etc.).

Secondly, there were variances within both groups with regards to increased overall frequency of providing teacher-directed OTR. This may suggest that individual differences in how participants personally self-reflected on their teaching practices and provision of OTRs may play a part in goal setting and personal growth or their experience in dealing with a variety of student behaviors. With additional sessions in the TeachLivE ${ }^{\mathrm{TM}}$ virtual learning environment, it is inferred that participants would continue upward trends to make even further pedagogical changes that would (a) increase teacher/student interactions, (b) further motivate students to become more involved in the lessons by providing higher rates of opportunities to respond, and (c) increase appropriate classroom management strategies to allow for all students to become involved and highly engaged in learning.

Lastly, self-reflection data consistently referenced how to further engage the students (avatars) in lessons and how to increase personal connections to get to know the avatars more. Several reflections were made on how to increase student motivation and direct attention to not take over class discussions. This data infers that participants began to take note of individual personalities and/or behaviors and how it is important to figure out how to engage all types of learners. With additional sessions in the TeachLivE ${ }^{\mathrm{TM}}$ virtual simulation, it is inferred that participants would continue these types of trends and eventually begin to make pedagogical changes that would (a) increase teacher/student interactions to engage students in how they best learn; (b) motivate students to become more engaged in lessons by providing higher rates of opportunities to respond, and (c) modify classroom management strategies to allow for all students to become involved and highly engaged in the lesson. 


\section{Discussion}

This exploratory case study provided pre-service teacher participants the opportunity to utilize the TeachLivE ${ }^{\mathrm{TM}}$ virtual simulation in an attempt to improve the use of instructional strategies, focusing primarily on providing OTR. When teachers increase their rates of providing opportunities to respond, student on-task behavior and correct responses increase, while disruptive behavior decreases [17,19,25-27]. Pre-service educators who are taught, coached, and given ample time to practice such teaching strategies are likely to see an increase in student learning and an overall improvement in classroom behavior.

Providing ample OTR that challenge and facilitate student achievement and engagement in lessons is crucial for classrooms today as research has confirmed that for students with high incidence disabilities (i.e., learning disabilities), three to five teacher-directed OTR per minute are associated with positive student outcomes both academically and behaviorally [22]. Allowing pre-service teachers to practice and fine-tune this skill in combination with immediate after-action review better prepares pre-service educators for realistic classroom expectations. Teaching the importance of self-reflection on pedagogical practices encourages pre-teachers to revisit instructional experiences, maximize construction of meaning for improved instruction, increase recognition of areas that need strengthening, and reconstruct teaching actions that bridge experience/learning, pushing one to evaluate assumptions and beliefs leading to active inquiry that allows for formulation of future actions $[11,28,29]$.

Instructional coaching allows mentor teachers to support pre-service educators during their teacher education program as it supports course content and allows for support through modeling, observation, implementation, and refinement of teaching strategies and practices. Additionally, instructional coaching allows for increased reflection and discussion about what happened, what should have happened, and needed changes [30]. This pilot study revealed that both groups of participants had some increase with or without instructional coaching. This could be in part to the mere repeated exposure to the virtual simulation and the researchers presence during each session and the self-reflections that were required after each virtual simulation. All participants provided OTR above the suggested rate of three to five OTR/minute indicating that practice in this type of environment with repeated teaching trials using the same lesson proved effective in learning the basic aspects of teaching, and may also indicate effective coursework and practice in prior teacher preparation courses.

This study has vast potential for transferability to other areas of teacher preparation scenarios for both general and special educators related to the rate to which OTR are provided when teaching specific subject matter/strategies, behavior/classroom management, social skill instruction, and so forth. As research continues to emerge regarding the use TeachLivE ${ }^{\mathrm{TM}}$ and other virtual simulations combined with instructional coaching, one can assume that implications for specific practice, use, and efficacy will continue to emerge.

\section{Limitations}

There are a number of benefits to using the TeachLivE ${ }^{\mathrm{TM}}$ virtual simulation with pre-service special educators but, because such environments have the potential to make significant impacts on the way that pre-service special educators are prepared, it is important to consider a longitudinal research study following pre-service teachers' throughout the course of their entire teacher preparation program and into their first year and subsequent years of teaching. A longitudinal study with a larger sample size would be beneficial to see specific long-term impacts that the TeachLivE ${ }^{\mathrm{TM}}$ virtual simulations may have on individualized teaching practices. This in combination with instructional coaching and self-reflection would glean information regarding the utility and usefulness of TeachLivE ${ }^{\mathrm{TM}}$ simulations. Such research would not only benefit teaching outcomes and teacher preparation programs as a whole, but would allow for the ability to observe the individualized presence or absence of skills among pre-service special education teachers. 


\section{Conclusions}

There are a number of benefits with regard to the utilization of the TeachLivE ${ }^{\mathrm{TM}}$ virtual simulation with pre-service special educators. It is no question that the curriculum of teacher education requires a shift in focus from what teachers know to a greater focus on what teachers do [31,32]. Continuing research on how to develop specific teaching skills within such a setting would not only benefit teaching outcomes and teacher preparation programs as a whole, but also allow for the observation of individualized presence or absence of specific teaching skills. Virtual learning environments have the potential to make a significant impact on the way that pre-service educators prepare for work in all types of classrooms (general education, special education, and inclusive). It is important to consider a longitudinal research study following pre-service general and special educators throughout the course of their entire teacher preparation program and into their first year and/or subsequent years of teaching. This has the potential to recognize specific long-term impacts of the TeachLivE ${ }^{\mathrm{TM}}$ virtual simulations and what it may provide with regards to individualized teaching practices in various content/subject areas.

It is essential to create learning pathways to develop skills and master content so that diverse groups of students, including those with special needs, can be effectively taught [32,33]. Strong preparation that encourages instructional change not only requires awareness of context and teaching practices, but an understanding of various contexts involved in the construction and acquisition of knowledge. This instruction must heighten initial effectiveness and increase the likelihood of novice teachers to stay on the job long enough to become experienced and effective.

Virtual simulations have the potential to create experiential practica for pre-service teachers and to positively impact teacher preparation by allowing for the improvement of specific pedagogical skills through a simulated approach. Early and advanced preparation for future teachers is crucial and it is the responsibility of teacher preparation programs to utilize and facilitate experiences for increased practice through virtual simulation platforms such as TeachLivE ${ }^{\mathrm{TM}}$ as it has the potential to pinpoint and allow for individualized teaching and coaching of classroom practices.

Conflicts of Interest: The researcher declares no conflict of interest.

\section{References}

1. Beare, P.; Marshall, J.; Torgerson, C.; Tracz, S.; Chiero, C. Toward a culture of evidence: Factors affecting survey assessment of teacher preparation. Teach. Educ. Q. 2012, 39, 159-173.

2. Lee, Y.; Patterson, P.P.; Vega, L.A. Perils to self-efficacy perceptions and teacher-preparation quality among special education intern teachers. Teach. Educ. Q. 2011, 38, 61-76.

3. Dieker, L.; Hynes, M.; Hughes, C.; Smith, E. Implications of mixed reality and simulation technologies on special education and teacher preparation. Focus Except. Child. 2008, 40, 1-20.

4. King-Sears, M.E.; Carran, D.T.; Dammann, S.N.; Arter, P.S. Multi-site analysis of special education and general education student teachers' skill ratings for working with students with disabilities. Teach. Educ. Q. 2012, 39, 131-149.

5. Katsiyannis, A.; Zhang, D.; Conroy, M.A. Availability of special education teachers: Trends and tests. Remedial Spec. Educ. 2003, 24, 246-253. [CrossRef]

6. Ingersoll, R.; Merrill, L.; May, H. Retaining teachers: How preparation matters. Educ. Leadersh. 2012, 69, 30-34.

7. Darling-Hammond, L. Teacher Quality and Student Achievement: A Review of State Policy Evidence; Center for the Study of Teaching and Policy, University of Washington: Seattle, WA, USA, 1999.

8. Ayres, K. Using video-based anchored instruction to teach functional behavior analysis. J. Spec. Educ. Technol. 2008, 23, 50-55.

9. Rieg, S.; Wilson, B. An investigation of the instructional pedagogy and assessment strategies used by teacher educators in two universities within a state system of higher education. Education 2009, 130, 277-294.

10. Boggs, J.G.; Mickel, A.E.; Holtom, B.C. Experiential learning through interactive drama: An alternative to student role plays. J. Manag. Educ. 2007, 31, 832-858. [CrossRef] 
11. Collet, V.S. The gradual increase of responsibility model: Coaching for teacher change. Lit. Res. Instr. 2012, 51, 27-47. [CrossRef]

12. Britton, L.R.; Anderson, K.A. Peer coaching and pre-service teachers: Examining an underutilised concept. Teach. Teach. Educ. 2010, 26, 306-314. [CrossRef]

13. Baird, L.; Holland, P.; Deacon, S. Learning from action: Imbedding more learning into the performance fast enough to make a difference. Organ. Dyn. 1999, 27, 19-32. [CrossRef]

14. Darling-Hammond, L.; Bransford, J.; LePage, P. Preparing Teachers for a Changing World: What Teachers Should Learn and Be Able to Do; Jossey-Bass: San Francisco, CA, USA, 2005.

15. Capizzi, A.; Wehby, J.; Sandmel, K. Enhancing mentoring of teacher candidates through consultative feedback and self-evaluation of instructional delivery. Teach. Educ. Spec. Educ. 2010, 33, 191-212. [CrossRef]

16. Ferkis, M.; Belfiore, P.; Skinner, C. The effects of response repetitions on sight work acquisition for students with mild disabilities. J. Behav. Educ. 1997, 7, 307-324. [CrossRef]

17. Carnine, D.W. Effects of two teacher presentation rates on off-task behavior, answering correctly, and participation. J. Appl. Behav. Anal. 1976, 9, 199-206. [CrossRef] [PubMed]

18. Sutherland, K.S.; Wehby, J.H.; Yoder, P.J. Examination of the relationship between teacher praise and opportunities for students with EBD to respond to academic requests. J. Emot. Behav. Disord. 2002, 10, 5-13. [CrossRef]

19. Sutherland, K.S.; Wehby, J.H. Exploring the Relationship between Increased Opportunities to Respond to Academic Requests and the Academic and Behavioral Outcomes of Students with EBD A Review. Remedial Spec. Educ. 2001, 22, 113-121. [CrossRef]

20. Marshall, J.C.; Smart, J.B. Teachers' transformation to inquiry-based instructional practice. Creat. Educ. 2013, 4, 132-142. [CrossRef]

21. Haydon, T.; Conroy, M.A.; Scott, T.M.; Sindelar, P.T.; Barber, B.R.; Orlando, A.M. A comparison of three types of opportunities to respond on student academic and social behaviors. J. Emot. Behav. Disord. 2009, 18, 27-40. [CrossRef]

22. Macsuga-Gage, A.S.; Simonsen, B. Examining the effects of teacher-directed opportunities to respond on student outcomes: A systematic review of the literature. Educ. Treat. Child. 2015, 38, 211-239. [CrossRef]

23. Cavanaugh, B. Performance feedback and teachers' use of praise and opportunities to respond: A review of the literature. Educ. Treat. Child. 2013, 36, 111-136. [CrossRef]

24. Rademacher, J.A.; Pemberton, J.B.; Cheever, G.L. Focusing Together: Promoting Self-Management Skills in the Classroom; Edge Enterprises, Inc.: Lawrence, KS, USA, 2006.

25. Barbetta, P.M.; Heron, T.E.; Heward, W.L. Effects of active student response during error correction on the acquisition, maintenance, and generalization of sight words by students with developmental disabilities. J. Appl. Behav. Anal. 1993, 26, 111-119. [CrossRef] [PubMed]

26. Sutherland, K.S.; Alder, N.; Gunter, P.L. The effect of varying rates of opportunities to respond to academic requests on the classroom behavior of students with EBD. J. Emot. Behav. Disord. 2003, 11, 239-248. [CrossRef]

27. West, R.P.; Sloane, H.N. Teacher presentation rate and point delivery rate effects on classroom disruption, performance accuracy, and response rate. Behav. Modif. 1986, 10, 267-286. [CrossRef] [PubMed]

28. Mezirow, J. Transformative learning as discourse. J. Transform. Educ. 2003, 1, 58-63. [CrossRef]

29. Kitchenham, A. The evolution of John Mezirow's transformative learning theory. J. Transform. Educ. 2008, 6, 104-123. [CrossRef]

30. Knight, J. Coaching Approaches E Perspectives; Corwin Press: Thousand Oaks, CA, USA, 2009.

31. Ball, D.L. Bridging practices intertwining content and pedagogy in teaching and learning to teach. J. Teach. Educ. 2000, 51, 241-247. [CrossRef]

32. Ball, D.L.; Hill, C.H.; Bass, H. Knowing mathematics for teaching: Who knows mathematics well enough to teach third grade, and how can we decide. Am. Educ. 2005, 29, 14-46.

33. Payne, R. Special education teacher shortages: Barriers or lack of preparation? Int. J. Spec. Educ. 2005, 20, 88-91.

(C) 2018 by the author. Licensee MDPI, Basel, Switzerland. This article is an open access article distributed under the terms and conditions of the Creative Commons Attribution (CC BY) license (http://creativecommons.org/licenses/by/4.0/). 